\title{
Effect of Losartan and Amlodipine on Lung Function Status in Hypertensive Patients: A Randomized Control Trial
}

\author{
Nahar MN1ㄴ, Begum S², Ferdousi S ${ }^{3}$, Habib T4 \\ DOI: https://doi.org/10.3329/jafmc.v15i1.48640
}

\begin{abstract}
Introduction: Essential hypertension is associated with altered pulmonary function. Antihypertensive medication and lung function are also associated. Losartan (angiotensin II receptor blocker) and amlodipine (calcium channel blocker) are commonly used antihypertensive drugs.
\end{abstract}

Objectives: To evaluate the effects of antihypertensive drugs on lung function status in patients with essential hypertension.

Materials and Methods: This prospective observational study was carried out in the Department of Physiology of Bangabandhu Sheikh Mujib Medical University (BSMMU), Shahbag, Dhaka, from July 2012 to June 2013 on 100 newly diagnosed hypertensive patients without any antihypertensive medication (group B, age 30-55 years). They were selected from the Out Patient Department (OPD) of Cardiology, BSMMU, Dhaka. Age, sex and BMI matched 50 apparently healthy normotensive subjects were also studied as control (group A). Based on treatment, these study subjects were divided into two groups (B1 and B2). Group B1 included 50 patients received losartan $50 \mathrm{mg}$ daily and B2 included 50 patients received amlodipine $5 \mathrm{mg}$ daily. They were observed once before the treatment (B1a and B2a), after 3 months of medication (B1b and B2b) and after 6 months of medication (B1C and B2C). For assessing lung function status, Forced Vital Capacity (FVC), Forced Expiratory Volume in 1st second (FEV1) and Peak Expiratory Flow Rate (PEFR) were measured with a RMS computer based Spirometer.

Results: Mean FVC, FEV1 and PEFR were significantly lower in newly diagnosed hypertensive patients in comparison with that of healthy normotensive. Mean FVC, FEV1 and PEFR were found significantly higher in the group taking losartan and amlodipine for 6 months when compared to newly diagnosed but lower than those of controls.

Conclusion: Reduced lung function occurs in newly diagnosed hypertensive patients which was improved by treatment with losartan and amlodipine.

Key-words: Hypertensive patients, Lung function test.

\section{Introduction}

Hypertension is a sustained elevation of systemic arterial pressure ${ }^{1}$. Essential hypertension accounts for $90-95 \%$ of all cases of hypertension². Now a day's hypertension becomes a significant public health challenge throughout the world because of its high prevalence ${ }^{3}$. In Bangladesh the prevalence rate of hypertension is also very high and more than $20 \%$ of the adults have hypertension ${ }^{4}$. Hypertension has been linked to multiple other diseases including cardiac, cerebrovascular, renal and eye diseases ${ }^{5}$. Several studies showed that hypertension and lung function are also associated ${ }^{6-11}$. In addition, a wide variety of antihypertensive drugs are now available with different mechanism of action and certain antihypertensive drugs can affect pulmonary function. A randomized controlled trial have shown that angiotensin II receptor blocker have no effects on FEV1 or airway resistance in COPD patients ${ }^{12}$.

Another study revealed that angiotensin II receptor blocker slightly reduced bronchial hyperresponsiveness to methacholine in patients with bronchial asthma ${ }^{13}$. Several studies suggested that Calcium channel blockers have no adverse effects on resting airway function in patients with asthma ${ }^{14,15}$. Some studies revealed no significant broncho-dilatation 45 minutes after Calcium channel blocker administration in asymptomatic asthma patients ${ }^{16}$. On the other hand, another study observed improvement of airway resistance, peak expiratory flow rates and FEV1 after one and two hours of Calcium channel blocker administration in patients with bronchial asthma ${ }^{17}$. Although several investigators observed the effect of losartan and amlodipine on lung function separately no report compared the effect of losartan and amlodipine on lung function in newly diagnosed hypertensive patients. Therefore this study aimed to evaluate the lung function in untreated hypertensive patients and compare the effect of losartan and amlodipine on lung function.

\section{Materials and Methods}

This prospective randomized control trial was carried out in the Department of Physiology of Bangabandhu Sheikh Mujib Medical University (BSMMU), Shahbag, Dhaka, from July 2012 to June 2013. 100 newly diagnosed hypertensive patients aged 30-55 years were selected as study group (group B). Age, sex and $\mathrm{BMI}$ matched 50 apparently healthy normotensive subjects were also studied as control (group A). Based on treatment, these study subjects were divided into two groups (B1 and B2). Group B1 included 50 patients received losartan $50 \mathrm{mg}$ daily and B2 included 50 patients received amlodipine $5 \mathrm{mg}$ daily. They were observed once before treatment (B1a and B2a), after 3 months of medication (B1b and B2b) and after 6 months of medication

1. Lt Col Mst Nasrin Nahar, MBBS, MD, Assistant Professor of Physiology, AFMC, Dhaka (E-mail: nasrin101188@gmail.com) 2. Professor Shelina Begum, MBBS, MPhil, Professor and Chairman of Physiology, BSMMU, Shahbag, Dhaka 3. Professor Sultana Ferdousi, MBBS, MPhil, Department of Physiology, BSMMU, Shahbag, Dhaka 4. Dr Tamanna Habib, MBBS, MD, Assistant Professor, Department of Physiology, Anower Khan Modern Medical College and Hospital, Dhaka. 
(B1c and B2C). These patients were selected from the Out Patient Department of Cardiology, BSMMU.

Subjects with history of acute or chronic lung and chest wall disease e.g. pneumonia, tuberculosis, asthma, COPD, malignancy etc, history of coronary heart disease, diabetes mellitus, alcohol/ tobacco users and smokers were excluded from the study. After random selection of the subjects a detail personal, medical, family, socioeconomic, occupational and drug history were recorded in a preformed questionnaire and thorough physical examinations were done and documented. For the assessment of lung function FVC, FEV1 and PEFR were measured with a RMS computer based Spirometer. Then all the patients were requested to attend the Department of Physiology of BSMMU, again after 3 months and after 6 months of antihypertensive medication, to have the assessment of the above mentioned study variables. For statistical analysis independent sample ' $t$ ' test and paired sample 't' test were performed by using SPSS for windows version 16.0 as applicable. $P$ value $<0.05$ was accepted as level of significance.

\section{Results}

The mean of the percentages of predicted values of $F V C$, FEV1 and PEFR were significantly lower in group $\mathrm{B} 1 \mathrm{a}, \mathrm{B} 1 \mathrm{~b}$ and $B 1 c$ respectively than those of control. In addition, the mean percentage of predicted values of FVC, FEV1 and PEFR were significantly increased in group $\mathrm{B} 1 \mathrm{~b}$ and $\mathrm{B} 1 \mathrm{c}$ in comparison to their corresponding base line value of group B1a (Table-I). The mean of the percentages of predicted values of FVC, FEV1 and PEFR were significantly lower in group B2a, B2b and B2c respectively than those of control. In addition, the mean percentage of predicted values of $F V C$ and $F E V 1$ were significantly decreased in group $B 2 b$ and $\mathrm{B} 2 \mathrm{C}$ in comparison to their corresponding base line value B1a. But the mean percentage of predicted value of PEFR was non significantly increased in group B2b and B2c in comparison to their corresponding base line values of group B2a (Table-II).

Table-l: Percentages of predicted values of FVC, FEV1 and PEFR in different groups $(n=100)$

\begin{tabular}{|c|c|c|c|c|}
\hline Parameters & $\begin{array}{c}\text { Group A } \\
(\mathrm{n}=50)\end{array}$ & $B 1 a(n=50)$ & $\mathrm{B} 1 \mathrm{~b}(\mathrm{n}=50)$ & $B 1 c(n=50)$ \\
\hline FVC (L) & $88.9 \pm 0.827$ & $75.46 \pm 1.171$ & $76.84 \pm 0.993$ & $79.66 \pm 1.139$ \\
\hline FEV1 (L) & $90.62 \pm 0.772$ & $79.58 \pm 1.144$ & $81.16 \pm 1.082$ & $83.96 \pm 1.198$ \\
\hline PEFR (L/s) & $78.38 \pm 1.373$ & $76.38 \pm 1.527$ & $76.54 \pm 1.476$ & $78.9 \pm 1.369$ \\
\hline \multicolumn{5}{|c|}{ Statistical analysis } \\
\hline \multirow[t]{2}{*}{ Groups } & \multicolumn{4}{|c|}{$p$ value } \\
\hline & FVC & FEV1 & \multicolumn{2}{|c|}{ PEFR } \\
\hline A vs $\mathrm{B} 1 \mathrm{a} \varphi$ & $0.000^{\star \star *}$ & $0.000^{\star \star *}$ & \multicolumn{2}{|c|}{$0.333 \mathrm{~ns}$} \\
\hline A vs $B 1 b \varphi$ & $0.000^{* * *}$ & $0.000^{* * *}$ & \multicolumn{2}{|c|}{$0.364 \mathrm{~ns}$} \\
\hline$A$ vs $B 1 c \varphi$ & $0.000^{* \star *}$ & $0.000^{* * *}$ & \multicolumn{2}{|c|}{$0.789 \mathrm{~ns}$} \\
\hline $\mathrm{B} 1 \mathrm{a}$ vs $\mathrm{B} 1 \mathrm{~b} \Omega$ & $0.04^{*}$ & $0.000^{\star \star *}$ & \multicolumn{2}{|c|}{$0.881 \mathrm{~ns}$} \\
\hline $\mathrm{B} 1 \mathrm{~b}$ vs $\mathrm{B} 1 \mathrm{c} \Omega$ & $0.000^{* * *}$ & $0.000^{* * *}$ & \multicolumn{2}{|c|}{$0.009^{* *}$} \\
\hline $\mathrm{B} 1 \mathrm{a}$ vs $\mathrm{B} 1 \mathrm{c} \Omega$ & $0.000^{* \star *}$ & $0.000^{* \star *}$ & \multicolumn{2}{|c|}{$0.059 \mathrm{~ns}$} \\
\hline
\end{tabular}

Note: Data were expressed as mean \pm SE. $\varphi=$ independent sample 't' test, $\Omega=$ Paired sample't' test. Group A: Apparently healthy subjects (control group), Group B1a: Newly diagnosed hypertensive patients before treatment, Group B1b: After 3 months treatment with losartan, Group B1c: After 6 months treatment with losartan. ${ }^{* *}$ : Significant $(p \leq 0.001),{ }^{* *}$ : Significant $(p \leq 0.01)$, *: Significant $(p \leq 0.05)$, Ns : Nonsignificant, $n$ : Number

Table-II: Percentages of predicted values of FVC, FEV1 and PEFR in different groups $(n=100)$

\begin{tabular}{|c|c|c|c|c|}
\hline Parameters & Group $A(n=50)$ & B2a $(n=50)$ & B2b & B2C \\
\hline FVC (L) & $88.9 \pm 0.827$ & $73.9 \pm 1.037$ & $76.28 \pm 0.960$ & $78.12 \pm 0.970$ \\
\hline FEV1 (L) & $90.62 \pm 0.772$ & $79.38 \pm 1.157$ & $81.08 \pm 1.151$ & $83.3 \pm 1.041$ \\
\hline PEFR (L/s) & $78.38 \pm 1.373$ & $72.96 \pm 1.289$ & $73.5 \pm 1.235$ & $75.6 \pm 1.338$ \\
\hline \multicolumn{5}{|c|}{ Statistical analysis } \\
\hline \multirow[t]{2}{*}{ Groups } & \multicolumn{4}{|c|}{$p$ value } \\
\hline & FVC & FEV1 & \multicolumn{2}{|c|}{ PEFR } \\
\hline A vs B2a & $0.000^{\star \star \star}$ & $0.000^{\star \star *}$ & \multicolumn{2}{|c|}{$0.005^{\star *}$} \\
\hline$A$ vs $B 2 b \varphi$ & $0.000^{* \star *}$ & $0.000^{\star * \star}$ & \multicolumn{2}{|c|}{$0.010^{*}$} \\
\hline$A$ vs $B 2 c \varphi$ & $0.000^{\star \star \star}$ & $0.000^{\star * *}$ & \multicolumn{2}{|c|}{$0.150 \mathrm{~ns}$} \\
\hline$B 2 a$ vs $B 2 b \Omega$ & $0.000^{* * *}$ & $0.016^{*}$ & \multicolumn{2}{|c|}{$0.465 n s$} \\
\hline $\mathrm{B} 2 \mathrm{~b}$ vs $\mathrm{B} 2 \mathrm{c} \Omega$ & $0.000^{\star \star \star}$ & $0.000^{\star \star *}$ & \multicolumn{2}{|c|}{$0.055 \mathrm{~ns}$} \\
\hline$B 2 a$ vs $B 2 c \Omega$ & $0.000^{\star \star \star}$ & $0.000^{* * *}$ & \multicolumn{2}{|c|}{$0.033^{*}$} \\
\hline
\end{tabular}

Note: Data were expressed as mean \pm SE. $\varphi=$ independent sample 't' test, $\Omega=$ Paired sample 't' test. Group A: Apparently healthy subjects (control group), Group B2a: Newly diagnosed hypertensive patients before treatment, Group B2b: After 3 months treatment with amlodipine, Group B2c: After 6 months treatment with amlodipine. ${ }^{* * *}$ : Significant $(p \leq 0.001),{ }^{* *}$ : Significant $(p \leq 0.01)$, *: Significant $(p \leq 0.05)$, Ns: Nonsignificant, $n$ : Number.

\section{Discussion}

In the present study, values of the lung function parameters in healthy normotensive group were almost similar to other investigators ${ }^{7}$. The mean of the percentages of predicted values of FVC, FEV1 and PEFR were significantly lower in newly diagnosed hypertensive patients than those of apparently healthy subjects. Similar findings were also reported by investigators of other countries ${ }^{6-8,10,11,18,19}$. Again in this study the lower values of the mean percentages of predicted values of FVC and FEV1 were significantly improved after 3 months and 6 months treatment with losartan and amlodipine. In addition, the lower values of the mean percentages of predicted value of PEFR was nonsignificantly improved after 3 months and 6 months treatment with losartan and amlodipine. No similar findings were reported by other researchers.

Investigators suggested that the decrement of different ventilatory variables in essential hypertension may be associated with early left ventricular hypertrophy and moderately left ventricular dysfunction which may increase left atrial pressure. As a consequence, an elevation of pulmonary arterial pressure and interstitial edema in the lung leading to decreased compliance of the lung and mild restrictive disease ${ }^{5-7}$. Different investigators suggested various mechanisms for the improvement of lung function status in hypertensive patients after treatment with losartan. Angiotensin II causes contraction of smooth muscle 
in pulmonary arteries and veins ${ }^{1}$. It has been suggested that angiotensin II causes bronchoconstriction in mildly asthmatic patients possibly by a direct effect on airway smooth muscle or by release of bronchoconstrictor mediators such as endothelin ${ }^{20}$. Therefore Angiotensin II receptor blocker may reduce bronchoconstriction in symptomatic asthma patients ${ }^{21}$.

Different investigators suggested various mechanisms for the improvement of lung function status in hypertensive patients after treatment with amlodipine. Calcium causes smooth muscle contraction, degranulation of mast cells and secretion of mucous from different cells in the airway epithelium ${ }^{22}$. Calcium channel blockers are vasodilators and in hypertension it inhibits calcium influx into arterial smooth muscle cells ${ }^{23}$. It has been suggested that Calcium channel blocker may reduce bronchoconstriction by inhibition of contraction of bronchial smooth muscle and release of mediators from mast cells or polymorphonuclear neutrophils in asthma patients ${ }^{16}$. The exact mechanisms involved for the decrement of lung functions in hypertension and improvement after treatment with losartan and amlodipine in hypertensive groups of present study could not be elucidated from this type of study. However, it is assumed that all the above mentioned mechanisms may influence the degree of deterioration of these variables in hypertension patients and improvement after treatment with losartan and amlodipine.

\section{Conclusion}

The ventilatory variables decrease in newly diagnosed hypertensive patients and lung function status improves after treatment with losartan and amlodipine. This decrement may be associated with silent pulmonary disorders without presenting any pulmonary symptoms.

\section{References}

1. Barrett KE, Barman SM, Boitano S et al. Ganong's Review of Medical Physiology. 23rd ed. India: Tata McGraw Hill Education Private Ltd: 2010:544, 547, 557, 559, 587.

2. Hypertension Wikipedia. 2012. Available from: thttp://en.wikipedia.org].

3. Kearney PM, Whelton M, Reynolds K et al. Worldwide prevalence of hypertension: A systematic review. J Hypertens 2004; 22(1):11-9.

4. Shahriar I, Haque Z, Momen A. Patterns of antihypertensive drugs used in two postgraduate instituitions. Journal of Dhaka National Medical College and Hospital 2008; 13(1):41-4.

5. Schnabel E, Nowak D, Brasche $S$ et al. Association between lung function, hypertension and blood pressure medication. Respiratory Medicine 2011; 105:727-33.

6. Sparrow D, Weiss ST, Vokonas PS et al. Forced vital capacity and the risk of hypertension. The normative aging study. Am J Epidemiol 1988; 127(4):734-41.

7. Selby JV, Friedman GD, Quesenberry CP Jr. Precursors of essential hypertension: pulmonary function, heart rate, uric acid, serum cholesterol, and other serum chemistries. Am J Epidemiol 1989; 131(6):1017-27.
8. Enright PL, Kronmal RA, Smith VE et al. Reduced vital capacity in elderly persons with hypertension, coronary heart disease, or left ventricular hypertrophy: the cardiovascular health study. Chest 1995; 107(1):28-35.

9. Wu Y, Vollmer WM, Buist AS et al. Relationship between lung function and blood pressure in Chinese men and women of Beijing and Guangzhou. Int J Epidemiol 1998; 27:49-56.

10. Engstrom $G$, Wollmar $P$, Valind $S$ et al. Blood pressure increases between 55 and 68 years of age is inversely related to lung function: longitudinal results from the cohort study Men born in 1914. J Hypertens 2001; 19:1203-8.

11. Margretardottir OB, ThorleifssonSJ, Gudmundsson $G$ et al. Hypertension, systemic inflammation and body weight in relation to lung function impairment: An epidemiological study. COPD 2009; 6(4):250-5.

12. Andrease S, Herrmann-Lingen C, Raupach T et al. Angiotensin II blockers in obstructive pulmonary disease: a randomized controlled trial. Eur Respir J 2006; 27:972-9.

13. Tanaka H, Teramoto S, Oashi K et al. Effects of candesarton on cough and bronchial hyper responsiveness in mildly to moderately hypertensive patients with symptomatic asthma. Circulation 2001; 104:281-5.

14. Williams DO, Barnes PJ, Vickers HP et al. Effect of nifedipine on bronchomotor tone and histamine reactivity in asthma. Br Med J 1981; 283:348.

15. Gonzalez JM, Monice RC, Bloom K et al. Inhibition of airway reactivity by nifedipine in patients with coronary artery disease. Am Rev Respir Dis 1983; 127(2):155-7.

16. Cerrina J, Denjean A, Alexandre $G$ et al. Inhibition of exercise induced asthma by a calcium antagonist, nifedipine. Am Rev Respir Dis 1981; 123(2):156-60.

17. Patakas $D$, Vlachoianni $E$, Tsara $V$ et al. Nifedipine in bronchial asthma. J Allergy ClinImmunol 1983; 72(3):269-73.

18. Lindgarde F, Furo M, Ljung BO. A longitudinal study on the significance of environmental and individual factors associated with the development of essential hypertension. J EpidemiolComm Health 1987; 41:220-6.

19. Schroeder EB, Welch VL, Couper $D$ et al. Lung function and incident coronary heart disease. Am J Epidemiol 2003; 158(12):1171-81.

20. Millar EA, Angus RM, Hulks $G$ et al. Activity of the renin angiotensin system in acute severe asthma and the effect of angiotensin II on lung function. Thorax 1994; 49:492-5.

21. Myou S, Fujimara M, Kamio $Y$ et al. Effect of losartan, a type 1 angiotensin II receptor antagonist, on bronchial hyper responsiveness to methacholine in patients with bronchial asthma. Am J Respir Crit Care Med 2000; 162:40-4.

22. Lofdahl GC. Antihypertensive drugs and airway function, with special reference to calcium channel blockade. Journal of cardiovascular pharmacology 1989; 14(10):S40-S51.

23. Katzung BG, Masters SB, Trevor AJ. Basic and clinical pharmacology. 11thed. New Delhi: Tata McGraw Hill education private limited 2009:181. 